\title{
It Is About Time \\ Interracial Couples and Racialized Wait Times in Dining
}

\author{
Heather Dalmage \\ Roosevelt University, Chicago, IL, USA
}

Heather Dalmage is a professor of sociology and director of the Mansfield Institute for Social Justice. She is president-elect to the Society for the Study of Social

Problems. She is a former Fulbright Scholar to South Africa, University of KwaZulu-Natal.

\begin{abstract}
In this article, I explore "wait time" as a form of racial border patrolling experienced by interracial couples when they dine out. I am framing "wait time" as something imposed and intentional to exclude these couples. When interracial couples are together, they are conspicuous reminders that the borders of whiteness are permeable. Racial borders, upheld through legal and extra legal means, include the contested, patrolled and often hostile spaces near the colour line. Interracial couples dining in restaurants across the globe report in their online post-dining reviews that they experienced comparatively long wait times to be both being seated and served. They report seeing other patrons not being made to wait while they are made to wait. Much of the literature on wait time during leisure assumes a colour-blind backdrop. Exploring the historical construction of race, specifically racial borders, provides the context for understanding why interracial couples are made to wait. I begin with an overview of the historical construction and reinforcing of "exclusionary" borders of whiteness. Next, I outline digital discourse analysis and the context of the data collection: TripAdvisor. Finally, I analyze the TripAdvisor reviews written by interracial couples. Analysis of the reviews highlighting the border patrolling of these couples is pervasive: "Wait time," poor service, and being rushed out are three ways interracial couples' experience being excluded. At stake is not just the time lost or the energy of dealing with negative emotions associated with racialized waiting, at stake is humanity.
\end{abstract}

\section{KEYWORDS}

TripAdvisor, interracial, border patrolling, racial borders, "wait time," time, racial categories, whiteness 
Time is lived subjectively: It flies and drags; it is squandered and taken away. We waste time and have it taken from us. Time, mobilized through prison sentences, alienating work, forced service or long wait times for services and goods, is an "operator of punishment" (Foucault, 1977, p. 108). Time is about power exercised in myriad ways, written into social structure. In the context of a White supremacist world, racialized Others "are literally made to wait for goods and services that are delivered first to members of the dominant group" (Hanchard, 1999, p. 256). "Wait time" is deployed as a weapon of whiteness and used to create and maintain "exclusionary, gated moral communities protected by temporal, no less than spatial, walls" (Mills, 2014, p. 30). The historical context of "wait time" includes the partitioning of humans, time and space through violence and dehumanization and maintained through institutional and individual practices (Lipsitz, 2007; Mills, 2014). The walls or borders of hierarchical racial categories are recognized and policed, demarcating "usand-them." Upholding racial categories requires "policing of the borders, a maintenance of the boundaries between 'one's own kind' and others" (Ferber, 1998, pp. 123-124). "Wait time" is used as one form of border patrolling, and like all time, it is "felt" or perceived based on an individual's cumulative experiences and awareness of the racial context. How we experience "wait time" will depend upon the context in which we are made to wait.

In this article, I explore "wait time" as a form of racial border patrolling experienced by interracial couples when they dine out. Thus, I am framing "wait time" as something imposed and intentional to exclude interracial couples. When interracial couples are together, they are conspicuous reminders that the borders and walls of whiteness are permeable. Racial borders, upheld through legal and extra legal means, include the contested, patrolled and often hostile spaces near the colour line. Border patrolling or policing can take many forms-some less subtle than others-including stares, comments, negative service (including being made to wait, while others are not being made to wait), being shunned and physical violence (Childs, 2005, 2016; Dalmage, 2000, 2018a, 2018b; Mills, 2014). Historical creations, borders have become institutionalized and internalized (Dalmage, 2000, p. 36). The borders are written into the rituals and practices of daily life (Bourdieu, 1977). Research shows that interracial couples, seen as a "social unit," will "evoke a neural disgust response" in single race people (Skinner \& Hudac, 2017, p. 68). The feelings of disgust, grounded in a racial habitus (Bonilla-Silva, Embrick, \& Goar, 2006), develop in a world in which racial boundaries wrap deeply held beliefs about humanity. Those crossing the racial boundaries are dehumanized, and people are not as willing to help those they have dehumanized (Cuddy, Rock \& Norton, 2007, cited in Skinner \& Hudac, 2017). Of course, being helped or served is central to the dining out experience.

Given the unique position of interracial couples in a system of whiteness, interracial couples experience and think about dining out and leisure time in a way that is "distinct from those of same-race couples and families" (Hibbler \& Shinew, 2002, p. 145). The fear and enactment of border patrolling and racism mediates their leisure time together and does not allow for relaxation, rather they experience stress and a confirmation of their outsider status (Dalmage, 2000; Hibbler \& Shinew, 2002; Stephenson \& Hughes, 2005; Torabian \& Miller, 2017). 
Interracial couples dining in restaurants across the globe report in their online postdining reviews that they experienced comparatively long wait times to be both being seated and served. They report seeing other patrons not being made to wait while they are made to wait. Much of the literature on wait time during leisure assumes wait times are an outcome of unintentional arrangements and actions (Cheng \& Tsai, 2014; Janakiraman, Meyer, \& Hoch, 2011; Ledbetter, Mohamed-Ameen, Oglesby, \& Boyce, 2013; Sulek \& Hensley, 2004; Wexler, 2015). These approaches to waiting recognize the negative emotional experience of waiting but do not address the intentionality of racialized "wait time." Thus, they propose colour-blind solutions. According to Wexler (2015), for instance, businesses ought to manage the "collective temporal experience." A "collective" assumes a togetherness; racialized "wait time" is intended to exclude undesirables from the collective. When interracial couples are in restaurants and are able to see and compare their experiences to the collective, their time slows and their distrust of the collective grows (see Hooker, 2009). Sulek and Hensley (2004) conducted research to explore the role of perceived fairness in the perception of wait time. Noting that when waiting is perceived as unfair it can 'act as a spoiler', and be experienced as 'a personal affront'; they do not recognize the intentionality of those wielding racialized "wait time" as an important factor in shaping perceptions of those being made to wait. When discussions of fairness are framed in a colour-blind manner, the intentional use of "wait time" is ignored and the experiences of border patrolling are missed.

In turn, because interracial couples experience and have awareness of racialized "wait time" deployed as a form of border patrolling, they also develop an expectation of injustice and thus need for watchfulness. The watchfulness creates time to slow and become thick, and individuals experience time negatively (Ledbetter et al., 2013; Wexler, 2015). Racialized "wait time" is experienced comparatively and within the context of "accumulated historical experiences" (Feagin, 1991, p. 114), not as a one-off slight (Mahadeo, 2018). Racialized "wait time" is not a problem businesses will fix or be able to manage by introducing new technology or other distractions. Rather, racialized "wait time" is intentional and central to whiteness, rooted in three European (White) projects: the partitioning of humans, space and time.

Through an analysis of the reviews, I illustrate how "wait times" are deployed and experienced by those at whom "wait time" is aimed. I argue that interracial couples are not just made to wait-the waiting is used to push them out of space (in this instance, the restaurant), away from the boundaries of whiteness. I begin with an overview of the construction and reinforcing of "exclusionary" walls of whiteness through the partitioning of humans, time and space. Next, I outline digital discourse analysis and the context of the data collection: TripAdvisor. Finally, I analyze the TripAdvisor reviews as written by interracial couples about their experiences dining and waiting to show how "wait time" is used as a weapon. At stake is not just the time lost or the energy of dealing with negative emotions associated with racialized waiting, at stake is humanity.

\section{Contextualizing Racial Borders}

The categorization of human beings, a largely European project, was rooted in mediaeval and Renaissance imaginations, organized through the Enlightenment, and dispersed around 
the globe and enacted through discourse, colonization, slavery and capitalism (West, 2002). The partitioning of humans laid the structural and ideological framework for partitioning both space and time to the benefit of Whites. Enlightenment thinkers were writing in a world already more than a century into trans-Atlantic slave trade and were creating a "common standard of judgment upon lesser peoples" (Mosse, 1978, p. 12). What began in the late 1600 s as the "scientific" creation of racial categories laden with value judgments, developed over a century and a half into a full-fledged ranking of human varieties. The "science" fed common sense or hegemonic understandings while justifying slavery and human exploitation already being built into the structure of nation states and capitalism. The categorization of humans was standardized through census counting and comparing nations and modernization (Loveman, 2014).

European writers collectively provided philosophy and "science" that created the global racial order and upheld the global slave order. In 1863/1864, Francois Bernier wrote of "remarkable differences" among humans that included "four or five species or races of men" that made up "the foundation for a new division of the earth" (p. 361). Carolus Linnaeus, in $1735 / 1964$, wrote that the highest of these human species should be "the governor and subjugator of" the "lesser varieties" (Baum, 2006, p. 65). By the end of the eighteenth century, concern for the bleeding of the boundaries and the need to patrol the borders was made explicit when Johann Blumenbach wrote that Whites (Caucasians) must be careful because "it's very easy to degenerate into brown, but very difficult for dark to become white" (p. 205). By the mid-1800s, Sir Arthur de Gobineau, a well-connected French traveller, aristocrat and long-time friend of Alexis de Tocqueville wrote about his concern for White purity and wrote that "race mixing leads to the degeneration of the race through a decline in the quality of its blood" (James, 2016). Racial purity became a defining aspect of whiteness and provided a clear border to patrol (Dalmage, 2000; Davis, 1991).

Ideas of White racial purity were amplified through nation building. In 1853, the first International Statistical Congress (ISC) met in Brussels and included statisticians from Europe and the Americas (Nixon, 1960). The goal of the ISC was to create a system to compare populations and nations around the world (Loveman, 2014). Of course, counting and comparing required agreed upon categories and the shared standards and ideals-ideals developed within the White (European) imaginary about human valuation and difference. The census was the modernizing vehicle allowing nations to compare themselves while developing national identities. Progress, modernity and superiority became synonymous with White and Western and was evident in the ways counting happened. Deep settler societies such as Australia (Veracini, 2007) chose to only count people they deemed White, while Argentina chose to report population statistics such that Americans and Europeans were highlighted, whereas Africans, Asians, and others were lumped together as "marginal or residual classifications" (Loveman, 2014, p. 184; see also Alberto \& Elena, 2016; Telles, 2014). The goal of each of these strategies was to remove or obscure "impure populations" (Lipsitz, 2007, p. 15) and "downplay the presence of 'uncivilised' peoples" (Loveman, 2014, p. 186), thus creating a national image that was White, Western and modern. Who counted and who was excluded was clarified as nations moved to be on the side of "Western" and "modern." 
Racialized time and space is based on the boundaried and hierarchical categorization of human beings and is built into the institutions and ideologies guiding the world and shaping the perceptions of time (Feagin, 1991; Lipsitz, 2007; Mills, 2014). The partitioning of humans, time and space was buttressed by scientific racism buoyed by the introduction of statistics played out through census taking and enacted through slavery, colonization and capitalism (see Al-Saji, 2013; Hanchard, 1999; Mills, 2014; Osborne, 1994; Prasad, 2013; Zerubavel, 1982). Cumulatively, these activities, ideas and institutionalized practices cemented whiteness as a global phenomenon. How we understand and perceive time depends upon the context in which we experience the present, remember the past and imagine the future (Feagin, 1991; Mahadeo, 2018). The experience of waiting is perceived in a context in which time is a weapon of White supremacy, the enactment of inequality (Foucault, 1977; Mahadeo, 2018; Mills, 2014).

\section{On TripAdvisor: The Site of the Research}

TripAdvisor reports itself to be "the world's largest travel site," with "630 million reviews and opinions," "455 million average unique monthly visitors" and "over 7.5 million accommodations, airlines, attractions, and restaurants" (TripAdvisor, 2018). Travellers, diners and others can access forums, reviews and read establishment responses to reviews and get help to "make the right choice when you shop for hotels, restaurants and attractions" (TripAdvisor, 2018). The site allows users to read reviews prior to dining and then write their own review afterward, so others may read and "extract useful insights" (Lei \& Law, 2015).

While users and researchers have many online review sites to explore (e.g., Yelp, Reddit, Lonely Planet, Facebook and Fodors), the TripAdvisor platform has two important affordances for understanding "wait time" and border patrolling in the dining experience. First, the TripAdvisor platform is public, when reviews are posted, anyone accessing TripAdvisor can read the review. Facebook, for instance, is built on a platform that uses networking through "friend" connections and "groups" - not all information posted is available to all users making access to a variety of experiences across space and time limited. Second, unlike platforms such as Yelp and Facebook, TripAdvisor allows for a single-word search across a range of geographic locations, including "world wide." A search for interracial, for instance, will return all posted reviews that include that particular word. Facebook's platform is not organized around dining or leisure or word searches, and Yelp's platform is organized for geographic searches, not "identity" word searches. Using a digital discourse analysis (Recuber, 2017), I will show that interracial couples experience and perceive "wait time" in restaurant dining as racialized and negative in comparison with service they see given to other diners. Digital discourse analysis is a "method [that] seeks to deeply understand one aspect of social life online: how meaning gets made through texts. This includes systematically collecting, reading, and analyzing ... sites of online discourse that are across the Web" (Recuber, 2017, p. 49). TripAdvisor is a useful platform to access the written reviews that include the experiences of interracial couples dining across the globe. Using digital discourse analysis, I am able to critique the affordances and constraints of the TripAdvisor platform, as I access the data that are not accessible through the other platforms. 


\section{Reviews}

After dining, a reviewer can log on to TripAdvisor and write a review. Above the review section in bold type is the sentence: "Your first-hand experiences really help other travellers. Thanks!" Reviewers are told to enter a "Title of your review," and then "summarise your visit or highlight an interesting detail." The reviewer is then prompted to write at least 100 characters on "Tell people about your experience, describe the place or activity, recommendations for travellers?" Reviewers are warned that if they violate the rules of the TripAdvisor "global community," the review may be removed. There is no public record of removed reviews, but from time to time, the process is made public. For instance, a business owner in the United Kingdom wanted TripAdvisor to remove a review. While TripAdvisor initially fought the removal, they relented stating that the reviewer had not actually stayed, but rather merely toured the business. The removed review included the following language: "I think I'll be staying away and would recommend to any other 'ethnics' to do the same. I don't think they like our sort around here" (Gerrard, 2010). The practice of removing reviews because people did not actually "stay" matters a great deal since racialized "wait time" is a weapon used to push interracial couples to leave restaurants without service. In short, the results captured for this research include the reviews TripAdvisor deemed okay to be posted.

As part of the review, TripAdvisor requires reviewers to give a numeric rating between 5 and 1 ( 5 = excellent, $4=$ very good, $3=$ average, $2=$ poor, $1=$ terrible $)$. Jamerson $(2017)$ argues that the consumer-driven quantified ranking provides TripAdvisor with a way to appear trustworthy. They are able to show visitors "objectivity and rationality of hard numbers" (Jeacle \& Carter, 2011, p. 305) and numbers from other users. Through the review platform and numeric ranking, TripAdvisor is "able to engender discursive authority at both the individual and collective levels” (Jamerson, 2017, p. 120). TripAdvisor gives each business a "summary" score based on the ratings from all of their reviewers. Thus, when gathering data, the researcher is able to obtain the overall summary scores or rankings and compare those scores to the scores or rankings given by their sample group. When exploring the experiences of a particular self-identified group, then the numeric ranking can illustrate the differential experiences and perceptions.

\section{Data Collection}

On the TripAdvisor platform, I searched the following terms: Interracial, Inter-racial and Biracial, and under the geographic designation, I searched, "world wide." The search returned 233 reviews that involved interracial couples dining, travelling or touring between 2010 and 2017. This sample includes individuals who recognized the salience of the identity enough to mention one of the three terms in the review of their leisure travel, dining or touring. It took me 4 days, 30 July 2017 through 2 August 2017, to capture the entire 233 reviews. I cut-and-pasted each review into a one document and numbered them 1 to 233 . I then organized reviews according to location, date, numeric rankings by the reviewer and the average rankings, whether it was a review of a hotel/restaurant/other, and then I carefully coded each review for themes and patterns. I began by reading and coding each of the 233 reviews. Next, I read each review for themes with a critical lens on the ways the TripAdvisor platform shaped the content and meaning making. Finally, using the broad 
themes that arose from the careful read and coding, I analyzed, in depth, the context of the racialization of "wait time" and the reporting of racism experienced in the offline world in an online world platform.

\section{Overview of the Sample}

Of the 233 total reviews in the sample, 107 reviews were of restaurant dining experiences. Thirty-five of the reviews were of dining experiences in the United States and, 13 of the reviews, or $25 \%$ of the sample, were of restaurants across Europe, Asia and the Americas (Canada, Mexico, Central America and South America). Fifty-nine of the restaurants reviews (55\%) spoke of poor service and border patrolling by other diners, but they did not mention being made to wait. The other 48 (45\%) of restaurant reviews referred specifically to racialized "wait time," and 39 of those reviews explicitly wrote about their experience in comparison to other diners. After waiting, 12 people (or one fourth of reviewers in this sample) reported leaving without being served; 36 stayed. The summary rating (of all diners' reviews) for the 48 restaurants in this sample was 3.7 (very good); the summary rating of those same 48 restaurants by interracial couples was 1.3 (terrible). None of the restaurant reviews that mentioned "wait time" were given positive numeric rating. However, of the 59 restaurant reviews that did not mention wait time, 22 gave numeric ratings that were equal to or above the overall ratings for the reviewed restaurants. Close examination of the reviews with positive numeric ratings show that when interracial couples feel they are being treated "just like everyone else," they tend to rate the restaurant positively-even when they face border patrolling. For example, a couple gave a Connecticut restaurant five stars, stating that it was because, "We were treated like friends, and that alone was enough for us (we're an interracial family, some establishments aren't so nice about that.)" In another review, the couple stated, "The best thing about the restaurant was how welcomed we felt. We are an interracial family and people often stare at us ... but we felt welcome and not like we were an oddity in anyway." They gave the restaurant five stars. A couple dining in Seattle, WA, wrote, "As an interracial couple we were treated like everyone else." They gave the restaurant four stars. A couple who dined at a buffet restaurant in Oklahoma wrote, "My warning is, if you are in an interracial relationship be prepared for the looks and stares instantly. Just ignore all that jazz and treat yourself to some amazing home cooked food." They still gave the restaurant five stars. And, finally, the following couple gave the restaurant five stars and wrote,

All of the employees we encountered were genuinely nice. Service was great . . Seems a few of the customers in this diner haven't seen an interracial couple before. Got some stares... it was mostly older white men. It didn't bother us and we didn't let it spoil our time at this diner.

Analyzing even the positively ranked restaurants makes it clear that when dining out, interracial couples remain watchful in the face of patrolling from a variety of places. Despite experiencing racial border patrolling, some reviewers still rated the restaurant as "excellent." This was not the case for the reviews that cited difficulties with being made to wait indicating that "wait time" may be more negatively felt and effective as a tool for policing racial borders. 


\section{Analysis of the Reviews}

The process of dining out includes several points at which waiting is expected to happen. We wait to be seated, to be served and may wait for the check or bill. Each of these points serves as sites for the mobilization of "wait time" as a weapon. Each of these points presents sites for interracial couples to have to manage negative experiences and the thickening of time. The reviewers in this sample illustrate the mobilization of "wait time" in several ways: "wait time" is mobilized through cherry-picking and ignoring (or shunning), and these strategies may be used in tandem with poor or hostile service and attempts to "rush" the couple out.

\section{Cherry-Picking}

One method restaurants use when faced with unwanted or undesirable diners is to give long wait time estimates to dissuade them from staying. A study by Thompson shows that restaurants "cherry-pick" customers based on "deciding which customers should be served and which, if any, should be turned away" (Thompson, 2011, p. 202). In response to an international survey, restaurants self-reported giving diners longer estimated wait times to dissuade them from choosing to stay. The majority of the 384 restaurant respondents reported that they "prefer to overestimate the waiting time for large parties" with the hope they will choose to dine elsewhere (Thompson, 2011, p. 209). Thompson is examining the profit/cost rationality of cherry-picking based on, in this case, group size, it is of interest that when restaurants consider group size alone, they admit to using the intentional of "wait time" as a tool to control who dines in their restaurant. Interracial couples report experiencing cherry-picking as a form of racialized "wait time."

Diane and her partner dined in a four star rated (very good) restaurant in New Jersey, United States, in January 2016. After experiencing cherry-picking, Diane gave the restaurant one star (terrible) and wrote,

I have never been to a more racist establishment than this one. First, the chef and the woman working at the register told us it would take 20 minutes for our order. Then, we said "Ok, that's fine." Then, the chef looked us and said, "No, it will take 30-45 minutes more." . . . We decided to wait there and it only took less than 15 minutes to get our food. In fact, the chef threw our food on the table as if we were animals and turned his attention towards the other white customers.... With the other nonethnic people, the chef and the woman were SO SO SO friendly, and I was so surprised that there was an establishment in Princeton that treated white people so much better than non-white people. I seriously can't believe this happened to me. Was it because we were an interracial couple?

They were given a long estimated wait time. When they accepted that estimate, the restaurant upped the wait time again. When the wait time did not work to push them out, the restaurant utilized service practices that dehumanized the couple and did so in plain comparative sight of the "nonethnic" or "White" customers. And, finally, as happens when time is used as a weapon, this couple was forced into a dystopian reality in which the practice of Whiteness was so blatant that even previous experiences do not always provide an adequate emotional defence mechanism. They are forced into a space of disbelief. 


\section{Shunning or Ignoring}

Another way "wait time" is mobilized, and a variant of cherry-picking, is through the use of shunning or ignoring a couple until they give up on receiving service and decide to leave. This sometimes happens prior to being seated, and again once the couple is seated. In December 2016, Mari wrote about her experience at a restaurant in Maryland, United States. This restaurant had an overall rating of 3 (good), she rated it a 1 (terrible) and wrote,

We did not eat here. We were seated and not served. No one spoke to my husband or myself. After sitting patiently for 25 minutes for someone to come to our table, ask how we were doing, if we wanted drinks, smile or even make eye contact with us we got up and left. I feel as though we were racially profiled. By my husband and I being an interracial couple they did not want to serve us. This happened on December 4th 2016 around 10am. What made me most upset was there were plenty of waitresses asking other people all around us if they needed anything else. They were making it a point to let us know that we were unwanted! I will be writing to the corporate office! This is not right at all!!

Note the use of "patiently waited." In pointing out that they had patience, she is recognizing emotional energy required to remain in the restaurant. Far from enjoying their leisure time, their experience created thick time and the need to manage negative emotions. The couple experienced "wait time" in comparison to all the diners around them not made to wait. They could see "plenty of waitresses" serving other diners. After being ignored, the couple left. The action of ignoring was viewed as wilful and a message that they were being excluded-not wanted. The "wait time" worked to push out this couple.

Similarly, a couple dining in Lima, Peru, reported being ignored and, finally, decided to leave without being served. The reviewer gave the four star (very good) rated restaurant a 1 (terrible) and wrote,

My wife and I were seated promptly and watched as other couples who were seated shortly after us were given a menu whilst we waited. We waited 20-25 minutes until we decided to walk out. Personally I hate to attribute this level of service on the fact that we are an interracial couple but it was clearly evident. The couples that were given a menu were seated directly nearby us so it's evident we were ignored. Upon leaving the restaurant we were asked why we were leaving, we told the hostess that we were waiting and a menu was not given to us but it was given to the all white couples.

The ignoring of interracial couples actually highlights their visibility and makes the mobilization of "wait time" conspicuous. As was the case in the majority of reviews, the "wait time" was meted out to this couple, made more negative because they could observe White diners not having to wait. These experiences accumulate and inform future expectations and create a racialized lens through which "waiting" is perceived (see Mahadeo, 2018). Rather than relaxing, unwinding and building nice memories during this leisure activity, this couple becomes watchful while building memories steeped in the exclusionary practice of "wait time" as a form of border patrolling. 
In August 2013, an interracial couple arrived in Munich, Germany, late and looked for a place to eat. They chose a 3.5 rated (very good) restaurant, but after leaving without service, they rated it a 1 (terrible):

We arrived in Munich fairly late at night. We were staying at a different nearby hotel and the restaurant was the closest. We picked up menus from the front desk on the way to our table. We chose a table nearby everyone else at the restaurant. The restaurant wasn't crowded and didn't look busy and neither did the bar. We waited 10 minutes for the waitress on duty to come and at least say hello and welcome us. We didn't get so much as a look. She stopped at the table to our right and asked if they needed anything else, the family declined and she brought them their check. Five more minutes passed and two German men sat down at the table across from us, and the waitress was at their table within 2 minutes, took their order and returned within a few minutes with their beer. Still, no eye contact, no acknowledgement, nothing. By this time about 20 minutes had passed since we had seated ourselves and I was furious. It was completely obvious that she wanted nothing to do with a bi-racial American couple. I walked out and my husband stayed behind to politely ask her what the problem was. She cut him off saying "hold on I'm busy" and walked away. So he left as well.

The shunning, complete with lack of eye contact, becomes more pronounced to interracial couples as they observe differential treatment. The reviewers note, the differential in wait time and treatment occurs in ways that they observe themselves receiving comparatively worse service and longer waiting. The patrolling is used, as Mari stated, to make a point. The process of patrolling racial boundaries is often explicit and visible to those on the receiving end.

\section{Poor Service}

Race-based poor service patterns exist across the restaurant industry. In the United States, for instance, one study of 195 servers showed that on a self-reported survey, 38.5\% said that race is a factor in the level of service they provide (Brewster \& Rusche, 2014). Some restaurants, using both space and time, will seat a couple in a less desirable area of the restaurant and then ignore them or provide hostile service. When couples decided to stay, despite being shunned, the staff then embarked on poor and hostile service. Many reviewers site dishes and glasses being slammed or thrown onto the table. Kimberly and her boyfriend chose to dine at a 3.5 (very good) rated restaurant in Amsterdam in January 2017. After their experience, she gave the restaurant a rating of 1 (terrible). Her lengthy review provides detail about tactics used by the staff:

My boyfriend and I (he's white, I'm black) came here on the 1st January 2017 for his birthday. As we walked in there were loads of empty tables and after looking us up and down with a face of disgust the waitress (jet black hair, long pony tail) placed us right next to the front door and it was freezing. After seating us [neither] she, nor any other waiter asked for our order for up to 20 minutes even though they catered to everyone else. When a waiter eventually did, a man this time, he completely turned his back to me and ONLY spoke to my boyfriend. . 10 minutes after that ANOTHER waiter brought our drinks over, dumping them on the table so aggressively it spilt, of course with no apology. After 
about half an hour we eventually got our starter (which was lovely by the way, order the fried calamari rings if you do have a pleasant experience). We noticed that another couple seated behind us (also interracial) were having a similar negative experience . . . the original waitress came back, picking up our HOT plate so aggressively she skimmed my face with her arm and stormed off with no acknowledgment. At this point I asked for the bill and asked to leave... [it] was the first time I saw her smile while ever serving us this night. I was so angry I was shaking and reduced to tears. We told the manager of the place his staff were disgustingly rude and clearly made the two interracial couples incredibly uncomfortable and all he could say was "I believe you, this isn't the first time and I'm sorry, I know I have problems with my staff."-Me and my boyfriend were so shocked at his response that we could only thank him for understanding.

Kimberly outlines service that is hostile and verges on assault. The entire experience, dining out and celebrating a birthday, the memories and the stories this couple will shareare steeped in whiteness and border patrolling. Because racialized time is lived cumulatively, these racialized experiences will add to their need to be watchful.

In another instance, Nadine and her partner dined in a French Bistro in Missouri, United States, for a surprise dinner just before Valentine's Day. The Bistro had an overall rating of 4 (very good); Nadine gave the Bistro a 1 (terrible). She wrote,

My beau decided to surprise me for dinner Saturday with a pre-Valentine's Day meal at an authentic French restaurant since I'm a connoisseur of all things French. Although we arrived ten minutes prior to our reservation, we waited an additional 15 minutes on top of the 10. A couple that arrived after us was seated promptly while we continued to wait. After the couple switched tables, my beau inquired about the empty table and we were seated. Service for us was horrible. From our drinks being late to having our orders placed extremely slow while watching other latecomers receive prompt service was discouraging and left a residual bad taste in our mouths. Although the food was excellent, this interracial couple will patronise other authentic restaurants with better quality customer service. Shame on you [restaurant]. All customers should be treated with dignity and respect.

Nadine was made to wait despite having a reservation, chose to stay, and then received horrible service. Nadine's experience, seen through a comparative lens becomes part of her memories. Racism tainted and shaped their leisure time, and it gave them insight to see it more quickly in future situations. Of course, the seeing can make time thicker and the racialized "wait time" less manageable. It can also become part of the everyday ways of managing. This couple's memories are now permeated by racism, undermining the joy, relaxation and romance. In the end, the reviewer speaks directly to the process of dehumanization when she states: "All customers should be treated with dignity and respect."

\section{Rushed Out}

Finally, when the couple was not deterred by wait times and poor service, the staff employed a tactic in which the couple's time at the table would be reduced. In the following, an interracial 
couple went to a restaurant with a general rating of four (very good), after their experience, they rated the restaurant as two (poor). Carmen wrote,

My husband \& I went to the Restaurant on a recent Sunday to have a good meal and to enjoy the view and the small town ambience. We are a nice \& quiet but friendly couple. The only difference from the other customers is that we're interracial but in most of the northwest it's not an issue. The last two times we have eaten at the restaurant, we have felt unwelcome. The first time we passed it off, but when it happened this time, we wondered why it keeps happening. Halfway through our meal, the waitress brought our check and asked for payment. I nodded and smiled at her and put it on the side of the table. My husband and I were trying to enjoy our meal, which by the way was very mediocre, so we continued our conversation. When we entered we were two of the few customers there. The place started filling up but there were still at least half a dozen tables. The waitress kept hovering and I knew she wanted payment. At one point she came over and asked where the check was and then saw it in plain sight at the edge of the table. By that time we had finished our meal, but our coffee cups were still full. Trying to be polite, I said, "We were hoping to sit here and finish our coffee!" She replied, "of course!" and walked away. The owner was also hovering all around so we thought maybe the bum's rush was at her bequest. These things are sometimes hard to pin down, but I felt she was trying to rush us out. We won't go there again until it changes ownership.

Carmen does not specify how they were made to feel uncomfortable in prior visits but notes that being an interracial couple mattered. This time, beyond the discomfort, they were given the "bum's rush" and pushed out of the restaurant.

\section{Conclusion}

The concept of race, built into the ideologies and institutions over long centuries, has resulted in the pathologizing of those that cross racial borders (Childs, 2005; Dalmage, 2000; Skinner \& Hudac, 2017). The experiences of interracial couples must be "understood in a broader context than that established by the acceptance of traditional explanations" (Zuberi, 2011, p. 1585). While racial categories are made to appear natural, in fact, the experiences of interracial couples as reported in TripAdvisor reviews show that the borders of racial categories are being constructed and contested through myriad forms of border patrolling. Our avenues for understanding how race is reproduced as it reproduces inequality have changed. Less than 20 years ago, when interracial couples were planning to dine out they had little way of knowing how they might be treated in a particular restaurant. Some couples reported doing "drive bys" to make sure a restaurant was not all White, and some couples joined organizations for mixed race families to learn and share information about safe places to dine (Dalmage, 2000). Since the introduction of Web 2.0 and its interactive capabilities, interracial couples have turned to the web both to form community and to figure out how to stay safe during travel and dining (Dalmage, 2018b). In addition, in the past, when facing discrimination, interracial couples had few pathways for managing-both while facing discrimination and in following up after the fact (Child, 2005; Dalmage, 2000; Feagin, 1991). 
Calling out racism in the moment can escalate racist abuse and create an even more negative experience. Through the web, interracial couples and families have been able to connect around the globe and find places to call out the racism and border patrolling they are experiencing. Using TripAdvisor to review restaurants gives interracial couples a chance to make their experiences public without risking escalated racist abuse in-person. In addition, interracial couples planning to dine out can search restaurants to learn if others are facing racism or border patrolling and avoid the process of being made to wait, poor service or being rushed out.

Close analysis of the content of the reviews on the TripAdvisor platform helps to make visible and clarify the ways in which "wait time" is being used to both exclude and to uphold whiteness. The experiences of interracial couples in the offline world-reported by interracial couples in the online world in this specific travel-site platform-allows for a discourse analysis of the specific and shared experiences. The discourse analysis (with careful coding) provides a window into border patrolling, and the significance of "wait time" as a form of border patrolling is made visible.

While all diners will experience waiting, not all waiting is the same. Racialized "wait times" are intentional and deployed to exclude. Because they are a visible racial transgressor, living (and dining) across racial boundaries, interracial couples are punished and patrolled. Through observation and comparison, interracial couples are able to watch as they are being made to wait and other diners are not. As a result, even while enjoying a dining experience, their reviews show that they are watchful, aware of the myriad forms of patrolling (including stares and comments by other diners). When interracial couples go to restaurants, they carry with them the memories of past experiences, including how they have been treated. They experience "wait time" in comparative and cumulative perspective. As the analysis of the reviews show, the wait is experienced through a racial lens. A critical race analysis shows the ways that "wait time" developed alongside the partitioning of humans, time and space has been mobilized for the purpose of exclusion and upholding White privilege and power.

\section{REFERENCES}

Alberto, P., \& Elena, E. (2016). Introduction. In P. Alberto \& E. Elena (Eds.), Rethinking race in modern Argentina (pp. 1-24). New York, NY: Cambridge University Press.

Al-Saji, A. (2013). Too late: Racialized time and the closure of the past. Insights, 6(5), 2-13.

Baum, B. (2006). The rise and fall of the Caucasian race: A political history of racial identity. New York: New York University Press.

Bernier, F. (1864). A new division of the earth, according to the different species or races of men who inhabit it. In Memoirs read before the anthropological Society of London (Vol. 1, pp. 360-364). Trübner. Retrieved from https://archive.org/details/memoirsreadbefor01anth (Original work published 1863)

Blumenbach, Johann Friedrich. (1999). On the Natural Variety of Mankind. In P. Kitson (Ed.), Slavery, abolition, and emancipation: Writings in the British Romantic period: Theories of race (pp. 141-212). London: Pickerin and Chatto. 1999.

Bonilla-Silva, E., Embrick, D., \& Goar, C. (2006). When Whites flock together: The social psychology of White Habitus. Critical Sociology, 32, 229-253.

Bourdieu, P. (1977). Outline of a theory of practice. Cambridge, UK: Cambridge University Press.

Brewster, Z., \& Rusche, S. (2014). The effects of racialized workplace discourse on race-based service in full-service restaurants. Journal of Hospitality \& Tourism Research, 41, 398-414. 
Cheng, Y., \& Tsai, Y. (2014). Train delay and perceived-wait time: Passengers' perspective. Transport Reviews, 34, 710-729.

Childs, E. C. (2005). Navigating interracial borders: Black-White couples and their social worlds. New Brunswick, NJ: Rutgers University Press.

Childs, E. C. (2016). Mixing in the rainbow nation: Exploring contemporary attitudes towards interracial couples in South Africa. Sociological Imagination, 51, 13-32.

Dalmage, H. (2000). Tripping on the color line: Black-White multiracial families in a racially divided world. New Brunswick, NJ: Rutgers University Press.

Dalmage, H. (2018a). Mixed race families in South Africa: Naming and claiming a location. Journal of Intercultural Studies, 39, 399-413.

Dalmage, H. (2018b). Traveling across racial borders: TripAdvisor and the discursive strategies businesses use to deny racism. Sociology of Race and Ethnicity. Online publication. doi:10.1177/2332649218785919

Davis, F. J. (1991). Who is Black? One nation's definition. University Park: Penn State University Press.

Feagin, J. R. (1991). The continuing significance of race: Antiblack discrimination in public places. American Sociological Review, 56, 101-115.

Ferber, A. (1998). White man falling: Race, gender, and White supremacy. Boulder, CO: Rowman \& Littlefield.

Foucault, M. (1977). Discipline and punish: The birth of the prison. New York, NY: Pantheon Books.

Gerrard, N. (2010, September). TripAdvisor removes review alleging racism. The Caterer. Retrieved from https://www.thecaterer.com/articles/335374/tripadvisor-removes-review-alleging-racism

Hanchard, M. (1999). Afro-modernity: Temporality, politics, and the African diaspora. Public Culture, $11,245-268$.

Hibbler, D., \& Shinew, K. (2002). Interracial couples' experience of leisure: A social network approach. Journal of Leisure Research, 34, 135-156.

Hooker, J. (2009). Race and the politics of solidarity. Oxford, UK: Oxford University Press.

Jamerson, T. (2017). Digital orientalism: Tripadvisor and online travelers' tales. In J. Daniels, K. Gregory, \& T. M. Cottom (Eds.), Digital sociologies (pp. 119-137). Chicago, IL: Policy Press.

James, M. (2016). Race. In E. N. Zalta (Ed.), The Stanford encyclopedia of philosophy. Retrieved from https://plato.stanford.edu/archives/spr2016/entries/race/

Janakiraman, N., Meyer, R. J., \& Hoch, S. J. (2011). The psychology of decisions to abandon waits for service. Journal of Marketing Research, 48, 970-984.

Jeacle, I., \& Carter, C. (2011). In TripAdvisor we trust: Rankings, calculative regimes and abstract systems. Accounting, Organizations and Society, 36, 293-309.

Ledbetter, J. L., Mohamed-Ameen, A., Oglesby, J. M., \& Boyce, M. W. (2013). Your wait time from this point will be .... Practices for designing amusement park queues. Ergonomics in Design, 21, 22-28.

Lei, S., \& Law, R. (2015). Content analysis of TripAdvisor reviews on restaurants: A case study of Macau. Journal of Tourism, 16, 17-28.

Linnaeus, C. (1964). Systema naturae: Facsimile of the first edition (M. S. J. Engel-Ledeboer \& H. Engel, Trans.). Amsterdam, The Netherlands: Nieuwkoop: B. de Graaf. (Original work published 1735)

Lipsitz, G. (2007). The racialization of space and the spatialization of race. Landscape Journal, 26, $10-23$.

Loveman, M. (2014). National colors: Racial classification and the state in Latin America. New York, NY: Oxford University Press.

Mahadeo, R. (2018). Why is the time always right for white and wrong for us? How racialized youth make sense of whiteness and temporal inequality. Sociology of Race and Ethnicity. Online publication. doi:10.1177/2332649218770469

Mills, C. W. (2014). White time. Du Bois Review, 11, 27-42.

Mosse, G. L. (1978). Toward the final solution: A history of European racism. New York, NY: Howard Fertig.

Nixon, J. W. (1960). A history of the international statistical institute, 1885-1960. The Hague, The Netherlands: International Statistical Institute. 
Osborne, P. (1994). The politics of time. Radical Philosophy, 68, 3-9.

Prasad, R. (2013). "Time-sense": Railways and temporality in colonial India. Modern Asian Studies, $47,1252-1282$.

Recuber, T. (2017). Digital discourse analysis: Finding meaning in small online spaces. In J. Daniels, K. Gregory, \& T. M. Cottom (Eds.), Digital sociologies (pp. 47-60). Chicago, IL: Policy Press.

Skinner, A., \& Hudac, C. (2017). "Yuck, you disgust me!" Affective bias against interracial couples. Journal of Experimental Social Psychology, 68, 68-77.

Stephenson, M. L., \& Hughes, H. L. (2005). Racialised boundaries in tourism and travel: A case study of the UK Black Caribbean community. Leisure Studies, 23, 137-160.

Sulek, J. M., \& Hensley, R. L. (2004). The relative importance of food, atmosphere, and fairness of wait: The case of a full-service restaurant. Cornell Hotel and Restaurant Administration Quarterly, 45, $235-247$.

Telles, E. (2014). Pigmentocracies: Ethnicity, race, and color in Latin America. Chapel Hill: University of North Carolina Press.

Thompson, G. M. (2011). Cherry-picking customers by party size in restaurants. Journal of Service Research, 14, 201-213.

Torabian, P., \& Miller, M. C. (2017). Freedom of movement for all? Unpacking racialized travel experiences. Current Issues in Tourism, 20, 931-945.

TripAdvisor. (2018). Available from https://www.tripadvisor.com

Veracini, L. (2007). Historylessness: Australia as a settler colonial collective. Postcolonial Studies, 10, 271-285.

West, C. (2002). A genealogy of modern racism. In P. Essed \& D. T. Goldberg (Eds.), Race critical theories (pp. 90-112). Hoboken, NJ: Blackwell Press.

Wexler, M. N. (2015). Re-thinking queue culture: The commodification of thick time. The International Journal of Sociology and Social Policy, 35, 165-181.

Zerubavel, E. (1982). The standardization of time: A sociohistorical perspective. American Journal of Sociology, 88, 1-23.

Zuberi, T. (2011). Critical race theory of society. Connecticut Law Review, 43, 1573-1591. 